\title{
Site testing at Dome C: history and present status
}

\section{Jean Vernin, Abdelkrim Agabi, Eric Aristidi, Max Azouit, Merieme Chadid, Eric Fossat, Tatiana Sadibekova, Hervé Trinquet and Aziz Ziad}

LUAN, UMR 6525, Université de Nice - Sophia Antipolis, F-06108 Nice Cedex 1, France email: vernin@unice.fr

\section{Introduction}

The idea of starting an astronomical site testing in Antarctica began during a congress organized by French Académie des Sciences, in 1992, and entitled 'Recherches polairesUne Stratégie pour l'an 2000'. At this time, one of us (Vernin 1994) gave a proposal for an astronomical site testing in Antarctica. This proposal was rapidly followed by a meeting between Al Harper (from 'Center for Astrophysical Research in Antarctica', Chicago), Peter Gillingham (from the Anglo Australian Observatory, Australia) and Jean Vernin (from Nice University) at Lake Geneva, Wisconsin, in 1993. It was decided to investigate what was the astronomical quality of South Pole station, each institute bringing its own participation: CARA, the South Pole infrastructure, University of New South Wales, a PhD student and Nice University its expertise and instruments.

On September 7th, Mike Dopita and John Storey presented a proposal to Roger Gendrin (former head of Institut Polaire, Michel Glass (former IFRTP head) and Jean Vernin. Later, following the project of a French-Italian base to be setup at Dôme C, we presented the first France-Italian-Australian proposal for Astrophysics at Dôme C, Paris, November 11th 1994.

\section{South Pole site testing 1994-1995}

The first astronomical site testing at South Pole took place from April to August 1994. We investigated the surface layer, attaching many sets of microthermal probes at various altitude on a mast (Marks et al. 1996) and next year we launched 15 balloons instrumented with microthermal probes to assess the optical turbulence vertical profile (Marks et al. 1999). From this two year campaign, it appeared clearly that almost all the optical turbulence was concentrated within the first $200 \mathrm{~m}$ of the surface layer. The overall seeing was $1^{\prime \prime} .86$, but only $0^{\prime \prime} .37$ when excluding those first $200 \mathrm{~m}$.

From Fig. 1 (middle) one can see the huge injection of kinetic energy in the surface layer. This kinetic energy is mixing parcels of air with very large variation in potential temperature (refractive index) giving rise to huge optical turbulence (bottom).

It was thus clear that katabatic winds were inducing this important wind shear and that one had better to investigate antarctic sites where no katabatic winds were expected. Indeed, at South Pole, even if the terrain seems quite flat, there remains still some slope from Dôme A and Dôme C, which triggers such a flow.

\section{Summer-winter Dôme C site testing}

Site testing operations began at Dôme C in 1995 during the stay of one of us (JV). Operations started again during summers 2000 to 2004 during which many DIMM measurements were performed (Aristidi et al. 2003, 2005). One of the main conclusion is that 


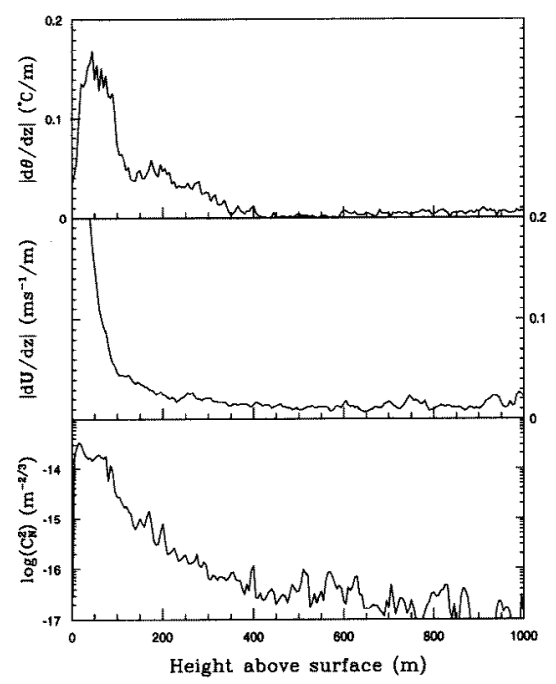

Figure 1. From top to bottom: vertical profile of the vertical gradient of the potential tempearature, the gradient of the wind velocity and the $C_{N}^{2}(h)$ within the first $\mathrm{km}$ above ice, as observed at South Pole. The same behavior is observed at Dôme C with less intensity and over a $30 \mathrm{~m}$ thick surface layer.

the median seeing is $0^{\prime \prime} .54$ and that every day during a $4 \mathrm{hr}$ period the seeing is better that $0^{\prime \prime} .5$ arcsec. For solar as well as IR astronomy (in bands were sky background from the sun is not annoying) Dôme $\mathrm{C}$ seems one of the best place in the world.

In 2005, AstroConcordia station was first open for winterover. One of us (AA), setup two DIMMs and launched successfully about 40 balloons (Azouit \& Vernin 2005) instrumented for $C_{N}^{2}(h)$ and $\mathbf{V}(\mathrm{h})$ profiles. Again, it became obvious that most of the turbulence was generated within the surface layer (Agabi et al. 2006), as it was found at South Pole, but, the depth of the SL is $30 \mathrm{~m}$ instead of $200 \mathrm{~m}$ and the optical turbulence is much less. This site is much better since almost all the large telescope have their mirror at such an altitude. For smaller telescopes, stiff platform might be envisaged in order to operate above the SL.

In 2006, a second winterover took place with the installation of two new instruments: the Generalized Seeing Monitor (GSM) and the Single Star Scidar (SSS). From the first instrument the outer scale of the wavefront of the light seems to be smaller than everywhere in the world, i.e., $10 \mathrm{~m}$. The SSS worked all along the whole polar night during about 400 hours, giving thousands of $C_{N}^{2}(h)$ and $\mathbf{V}(\mathrm{h})$ profiles.

\section{References}

Agabi, A., Aristidi, E., Azouit, M., et al. 2006, PASP, 118, 344

Aristidi, E., Agabi, A., Vernin, J., et al. 2003, A\&A (Letters), 406, L19

Aristidi, E., Agabi, A., Fossat, E., et al. 2005, A\& $A, 444,651$

Azouit, M., \& Vernin, J. 2005, PASP, 117, 536

Marks, R. D., Vernin, J., Azouit, M., et al. 1996, A\& AS, 118, 1

Marks, R. D., Vernin, J., Azouit, M., Manigault, J.F., \& Clevelin, C. 1999, A $\& A S$, 134, 161

Vernin, J. 1994, Recherches polaires - Une stratégie pour l'an 2000, Paris, 16-17 Décembre 1992 